\title{
DETERMINANTES DAS OSCILAÇÕES NO ENDIVIDAMENTO DAS EMPRESAS BRASILEIRAS
}

\section{DETERMINANTS OF THE SWINGS IN THE ENDEBTNESS OF BRAZILIAN COMPANIES}

\author{
IGOR BERNARDI SONZA \\ Universidade Federal de Santa Maria - UFSM \\ Professor Doutor Departamento de Administração - UFSM \\ Orcid: https://orcid.org/0000-0001-5403-3279 / E-mail: igorsonza@gmail.com \\ VAGNER NAYSINGER MACHADO \\ Universidade Federal de Santa Maria - UFSM \\ Doutorando em Administração - UFSM \\ Orcid: https://orcid.org/0000-0002-8111-8494 / E-mail: vagnernaysinger@gmail.com \\ Endereço: Av. Roraima, n. 1000, Cidade Universitária, Bairro: Camobi, Prédio 74-C, sala 4206, \\ Santa Maria - RS, CEP: 97105-900 \\ MARIA SILVIA PARDI LACRUZ \\ Universidade Federal de Santa Maria - UFSM \\ Professora Doutora - UFSM \\ Orcid: https://orcid.org/0000-0002-3966-0458 / E-mail: spardilacruz@gmail.com \\ ANDRIELI DA SILVA ROSA \\ Universidade Federal de Santa Maria - UFSM \\ Graduanda da Universidade Federal de Santa Maria - UFSM \\ Orcid: https://orcid.org/0000-0002-3847-1727 / E-mail: andrii.roosa@gmail.com
}

\section{RESUMO}

As consequências das dificuldades financeiras podem ser severas para as empresas em momentos de crise, gerando impactos institucionais nos negócios e resiliência no mercado de capitais, o que leva a uma maior demora em superá-la. Por esse motivo, o presente artigo busca analisar os determinantes das oscilações no endividamento das empresas brasileiras de capital aberto após a crise de 2008, identificando se os seus efeitos foram sentidos de forma diferenciada para grupos classificados de acordo com o nível de endividamento. Para esse fim, foram aplicadas análises de cluster e regressões lineares através de dados em painel não balanceados por GMM-Sys. Como resultado do estudo, foi identificado que, no pós-crise, as empresas ficaram mais receosas em buscar dívidas, também, os bancos começaram a ser mais rigorosos na concessão de crédito, sendo que as empresas maiores e mais arriscadas, com mais oportunidades de crescimento e menor rentabilidade, foram as mais suscetíveis a se endividarem nesse período. Com isso, contribui-se para discussão teórica-empírica quanto as implicações financeiras de um evento de crise, considerando as particularidades e diferenças entre empresas brasileiras.

Palavras-chave: Determinantes. Endividamento. Crise de 2008 


\begin{abstract}
The consequences of financial difficulties can be severe for companies in times of crisis, generating institutional impacts on business and resilience in the capital market, which leads to a greater delay in overcoming it. For this reason, the present paper seeks to analyze the determinants of the swings in the endebtness of Brazilian publicly traded companies after the 2008 crisis, identifying if their effects were felt differently for groups classified according to the level of indebtedness. For this purpose, cluster analyzes and linear regressions through unbalanced panel data by GMM-Sys were applied. As a result of the study, it was identified that, in the post-crisis period, companies were more afraid to seek debt; also, banks began to be stricter in lending. In consequence, larger and riskier companies, with more growth opportunities and lower profitability were the most susceptible to indebtedness in this period. In this way, it contributes to a theoretical-empirical discussion about the financial implications of a crisis event, considering the particularities and differences of Brazilian companies.
\end{abstract}

Key Words: Determinants. Endebtness. 2008 Crisis.

\title{
1 INTRODUÇÃO
}

A partir de 1990, deu-se o início de uma década de crescimento econômico e baixa inflação, aliviando a pressão nos bancos. Mas a liberação de crédito e o financiamento habitacional acabaram abrindo caminho para uma "bolha" imobiliária generalizada (ANNAD et al., 2013). Nesse contexto, a crise financeira que atingiu os Estados Unidos em 2008, conhecida como subprime, desencadeou prejuízos aos bancos e até quebra das instituições financeiras, causando, assim, um receio dos bancos para liberarem novos financiamentos, aumento dos juros, encarecimento dos créditos, paralisação nos investimentos das empresas, gerando, por consequência, uma redução de empregos (KAHLE; STULZ, 2013).

Essa crise, que atingiu os EUA, rapidamente se espalhou por outros países, sendo que esses apresentaram graus diferentes de exposição ao risco de contágio, de acordo com o nível de abertura de suas economias e participação de investimentos externos em seus mercados financeiros (MURATORI, 2015). As economias emergentes conseguiram se reestruturar mais rapidamente, mostrando indícios de que essa crise não atingiu as empresas na mesma proporção.

No Brasil, o início da crise de 2008 não teve uma magnitude considerável, afetando somente questões relacionadas à exportação, ao crédito e ao mercado acionário, gerando pouco desemprego e uma pequena desaceleração no crescimento econômico. Após esse período inicial, o efeito da crise financeira começou a ser sentido de fato em 2009, com a dificuldade de se obter divisas, prejudicando, assim, os financiamentos das empresas por limitação do crédito, ficando comprometidos os projetos de extensão das organizações. Outro ponto visível da crise financeira foi percebido quando analisada a situação fiscal, pois os gastos do governo causaram um desequilíbrio nas contas, aumentando cada vez mais a dívida pública e a inflação, gerando a desvalorização da moeda e um alto risco para quem pretendia investir, devido às incertezas geradas no mercado (COSTA, 2015).

Esse contexto de crise impactaria no endividamento das empresas, no sentido que, influenciaria nas decisões quanto a estrutura de capital das firmas (DE ANGELO; ROLL, 2015; RAJAN; ZINGALES, 1995). Isso porque, a partir desse momento, as firmas começaram a tomar medidas para manterem-se nesse período conturbado. As empresas que dependiam dos 
bancos não conseguiram diminuir suas despesas no primeiro ano, optando por reduzir o endividamento para poder enfrentar a crise, (KAHLE; STULZ, 2013). Nesse mesmo contexto, Mitchell e Pulvino (2012) acrescentaram que a crise financeira de 2008 causou uma diminuição repentina na alavancagem, onde dívidas de longo prazo acabaram se tornando dívidas de curto prazo.

Quando o preço e as condições para empréstimos bancários destinados às empresas são afetados por dificuldades financeiras, Hertzberg et al. (2011) mostraram que a saída seria uma redução de crédito e participação no mercado, contribuindo assim, para que essas empresas cumpram com o compromisso de assumir dívidas e se endividem menos. Esse período de desaceleração no endividamento das empresas foi sentido no Brasil até meados de 2012, indicando que a análise dos determinantes dessas oscilações pode ser importante para entender melhor a dinâmica da captação de recursos externos pelas empresas brasileiras no período pós-crise.

Devido a esse contexto, o presente trabalho busca analisar os determinantes das oscilações no endividamento das empresas brasileiras de capital aberto após a crise de 2008, identificando se os efeitos dessa crise foram sentidos de forma diferenciada para grupos classificados de acordo com o nível de endividamento. $O$ fato de conhecer onde os problemas financeiros ocorrem e poder agrupá-los por similaridade, facilita o entendimento da análise, tanto que Sokol (2017) argumenta que a literatura falha ao abordar as implicações financeiras de um fenômeno sem levar em consideração suas diferenças e peculiaridades.

O presente trabalho é dividido em cinco partes, sendo esta introdução, a primeira delas. Após, é a apresentada a revisão bibliográfica, descrevendo as principais inferências dos autores a respeito do tema, os dados e variáveis, a análise dos resultados e, por último, as considerações finais.

\section{REFERENCIAL TEÓRICO}

O endividamento é um instrumento importante para o incremento financeiro das empresas, pois utilizar capital de terceiros para financiar suas atividades e ter um retorno sobre este valor é o objetivo dos gestores financeiros. Mas essa estratégia pode gerar maiores custos da dívida, fazendo com que aumente a possibilidade de dificuldades financeiras, principalmente em momentos de crise (TIROLE, 2006). Para melhor descrever a revisão de literatura, essa seção é dividida em duas partes, como segue: (i) Endividamento e seus determinantes; e, (ii) Efeitos da crise no endividamento.

\subsection{ENDIVIDAMENTO E SEUS DETERMINANTES}

A estrutura de capital refere-se à composição das fontes de financiamento de uma empresa, oriundas de capitais de terceiros (exigível) e de capitais próprios (Patrimônio Líquido) (TIROLE, 2006). Existem duas grandes linhas clássicas antagônicas sobre essa composição. Modigliani e Miller (1958) afirmavam que, num mundo hipoteticamente sem impostos, o valor da empresa independe da sua estrutura de capital, ou seja, o valor de uma empresa depende da qualidade de seus ativos (investimentos), e não da forma como ela é financiada. Já a teoria de Trade off admite que, mediante uma combinação adequada de suas fontes de financiamento, uma empresa pode definir um valor mínimo para seu custo médio ponderado de capital (ponto ótimo do WACC - Weighted Average Capital Cost) (FRANK; GOYAL, 2009). 
A partir deste ponto ótimo, na medida em que o quociente entre capital de terceiros e capital próprio aumenta, apesar do benefício fiscal, a probabilidade de que a empresa seja incapaz de saldar seus compromissos também se eleva, gerando dificuldades financeiras. Para Andrade e Kaplan (1998), essas dificuldades financeiras não necessariamente são decorrentes de dificuldades econômicas, mas crises podem levar empresas a passarem por períodos conturbados. Contrariando os estudos de Lemmon et al. (2008), que identificaram uma estabilidade das dívidas ao longo do tempo, DeAngelo e Roll (2015) verificaram uma variação grande das dívidas sobre o ativo ao longo do tempo.

Neste contexto, estudos teóricos-empíricos investigaram possíveis determinantes do endividamento das empresas, enquanto estrutura de capital. Para Frank e Goyal (2009) e Rajan e Zingales (1995) aspectos como oportunidades de crescimento, rentabilidade, tangibilidade dos ativos e tamanho das empresas podem influenciar no endividamento. Nesta linha, Lang et al. (1996) sugere que empresas com altas expectativas de crescimento futuro devem usar uma quantidade maior de financiamento externo de capital. Por outro lado, ao verificar o efeito da alavancagem e da maturidade da dívida em decisões de financiamento em um painel de empresas de investimento do Reino Unido, no período de 1996 a 2003, Dang (2011) identificou que as empresas com alto crescimento têm incentivos para a redução do endividamento e essa redução não é afetada pelo encurtamento de vencimentos das dívidas. Verificou também que o endividamento tem efeito negativo sobre os investimentos, o que é consistente com a hipótese de investimento excessivo em relação ao papel disciplinador da alavancagem para empresas com oportunidades de crescimento limitadas.

Quanto a rentabilidade, Frank e Goyal (2009) argumentam que empresas com maior rentabilidade enfrentam menores custos esperados de dificuldades financeiras e acham os benefícios fiscais mais valiosos. Neste sentido, a perspectiva fiscal e de custos de falência prevê uma relação positiva entre a rentabilidade e o endividamento das firmas (FRANK; GOYAL, 2009). Contudo, para Dang (2011) de acordo com os pressupostos da teoria do Pecking Order a relação entre rentabilidade e endividamento seria negativa. Isto porque, tal teoria pressupõem uma hierárquica nas decisões quanto a estrutura de capital, em que para minimizar imperfeições do mercado, como a assimetria informacional, primeiro as empresas preferem financiar seus projetos com recursos próprios (MYERS, 1984).

Além disso, para Almeida e Campello (2007) a tangibilidade dos ativos afeta a capacidade de endividamento das empresas, isso porque, os ativos mais tangíveis acabam sustentando o financiamento externo. Nesta mesma linha, Dang (2011) e Frank e Goyal (2009) argumentam que ativos tangíveis representam um maior valor de garantia, o que fez com que sejam mais bem aceitos por financiadores externos. Ademais, os problemas e custos de agência da dívida seria minimizado, o que incentivaria o aumento do endividamento (ALMEIDA; CAMPELLO, 2007; FRANK; GOYAL, 2009).

Já quanto ao tamanho das firmas, Rajan e Zingales (1995) argumentam que empresas maiores tendem a minimizarem as assimetrias informacionais entre seus insiders e o mercado financeiro. Desta forma, grandes empresas enfrentam menores custos de agência relacionados à dívida, e menor risco de inadimplência (FRANK; GOYAL, 2009). Com isso, estão menos vulneráveis a informações assimétricas e o problema da seleção adversa (DANG, 2011), o que faz com que tenham maior facilidade de acesso aos mercados financeiros (FRANK; GOYAL, 2009).

Outro aspecto que pode determinar o endividamento das empresas é o risco do negócio. Para Toy et al. (1974) uma boa métrica para calcular esse risco é por meio da 
variabilidade do EBIT (Earnings Before Interest and taxes) em relação ao total de ativos da firma. O risco estaria associado a variabilidade dos resultados e uma possível necessidade de recursos externos (DUTRA et al., 2018), o que aumentaria o endividamento e o risco de falência (RAJAN; ZINGALES, 1995).

Ademais, o endividamento das empresas pode ser determinado pelas oscilações dos recebimentos totais de receitas. Para Frank e Goyal (2009) quanto maior as variações dos ganhos, maior a probabilidade de as empresas captarem recursos financeiros de terceiros. Incertezas quanto aos montantes de receitas, fazem com que as empresas busquem maior segurança financeira, por meio de financiamento externo de seus projetos (HARRIS; RAVIV, 1991).

Por fim, períodos de instabilidade econômica podem determinar a disposição das empresas em captarem recursos externos. Para Anand et al. (2013) o ambiente conturbado durante e pós períodos de crises financeiras, geram uma onda de cautela por parte de empresas quanto a novos projetos de investimentos. Para Bem-David et al. (2012), nesse contexto de crise, há uma retração das empresas quanto a captação de recursos por meio de financiamentos externos. Além disso, as instituições financiadoras acabam restringindo a disponibilidade de crédito, o que acaba por reduzir os níveis de endividamento das firmas (ANAND et al., 2013).

Neste sentido, as empresas com altos custos financeiros, optam por diminuir o endividamento em períodos de dificuldades financeiras. Nesse contexto, George e Hwang (2010) identificaram que os retornos negativos estão relacionados à intensificação das dificuldades financeiras e da alavancagem, onde as empresas com problemas financeiros e com elevados custos, optam por escolher um endividamento menor para evitar problemas, mas acabam mantendo o risco para suportar esses baixos custos.

\subsection{EFEITOS DA CRISE NO ENDIVIDAMENTO}

Grandes desacelerações econômicas são tipicamente precedidas por fenômenos de aumento das dívidas. No período anterior à crise de 2008, foi identificado um aumento expressivo do endividamento das empresas, devido ao crescimento exacerbado do crédito nos EUA, indicando que esse crescimento foi um prenúncio da crise financeira (SCHULARICK; TAYLOR, 2012). Após esse período, temendo prejuízos ainda maiores, houve uma redução nos créditos bancários, fazendo com que o financiamento esterno diminuísse consideravelmente no período pós-crise.

As consequências das dificuldades financeiras podem ser severas para as empresas em momentos de crise, gerando impactos institucionais nos negócios e resiliência no mercado de capitais, o que leva a uma maior demora em superá-la (ANNAD et al. 2013). Nesse mesmo contexto, os bancos continuariam obtendo vantagens se continuassem honrando seus compromissos em meio a uma crise financeira, com o apoio do governo, das agências patrocinadoras e com o aumento de depósitos, mas, mesmo assim, normalmente optam por restringir financiamentos (ACHARYA; MORA, 2015).

Durante a crise de 2008, os problemas financeiros aconteceram com maior frequência em empresas de maior endividamento, maior crescimento e saldos em caixas mais baixos, ou seja, aquelas mais suscetíveis a consequências negativas dos choques econômicos externos (BLISS et al., 2015). Nesse período, houve também restrições financeiras que atingiram as vendas, prejudicando a liquidez do mercado, que foram mais sentidas, segundo Beber e 
Pagano (2013), em países não americanos, pois a redução do endividamento foi maior e o retorno sobre as ações não foi significativamente positivo.

Quando o preço e as condições para empréstimos bancários destinados às empresas são afetados por crises financeiras, Hertzberg et al. (2011) mostraram que a saída seria uma redução de crédito e participação no mercado, contribuindo assim, para que essas empresas cumpram com o compromisso de assumir dívidas e se endividem menos. Mas Gilson (1997) identificou que os custos de transação desencorajam a renegociação da dívida nos períodos de crises. Como resultado, as empresas com dificuldades financeiras tendem a aumentar seu endividamento.

HO: Os determinantes das oscilações do endividamento afetaram de uma forma significativa as empresas de capital aberto brasileiras após a crise de 2008;

\section{METODOLOGIA}

Para atingir o objetivo do estudo, foram utilizados dados contábeis de empresas dos setores da Economatica ${ }^{\circledR}$. Conforme orienta Cooke (1989), devido às particularidades de suas operações, as empresas do setor financeiro foram excluídas da análise. Com isso, a amostra foi constituída por 480 empresas de capital aberto, não financeiras, ao longo de 20 anos (1995 a 2014), totalizando 4.585 empresas-ano, subdivididas em cinco clusters, onde o primeiro e o segundo apresentaram 793 e 909 observações, respectivamente, já o terceiro e o quarto foram constituídos por 1.347 e 533 observações e, por fim, o quinto apresentou 1.003 observações.

A análise foi dividida em três etapas. Na primeira, foi realizada uma análise de cluster onde, para cada empresa, foi obtida, através do site, a localização geográfica da matriz (onde existe a maior concentração das atividades financeiras), ou seja, foram levantados o endereço, o CEP, a cidade e o estado da sede de cada empresa, que foram integrados à base de dados. Através dessas informações, as empresas foram classificadas em cinco clusters de acordo com o grau de endividamento. Foi aplicada a análise de cluster de Ward para a amostra total, pois proporciona um agrupamento hierárquico, calculado pela soma de quadrados entre os grupamentos, resultando em amostras de tamanhos similares. Como resultado, os grupos $1 \mathrm{e}$ 2 foram formados por empresas do estado de São Paulo, no grupo 3 predominaram empresas do Norte, Nordeste e Sudeste (exclusive São Paulo), no grupo 4 predominaram empresas da região Centro-Oeste (com exceção de Mato Grosso do Sul e Distrito Federal) e uma minoria de empresas do estado de São Paulo. Por fim, no grupo 5 foram encontradas, principalmente, empresas da região Sul, do Distrito Federal e do Mato grosso do Sul.

Após, foi feita a estatística descritiva para analisar as características e peculiaridades de cada grupo. Por fim, foi identificada a influência dos determinantes financeiros no endividamento. Para a obtenção deste resultado, foram aplicadas regressões lineares através de dados em painel não balanceados por GMM-Sys (Método dos Momentos Generalizado Sistêmico). Os instrumentos utilizados foram as variáveis explicativas defasadas, conforme proposto por Almeida et al. (2010). Este modelo foi escolhido, pois, nos estudos que possuem mais de três observações por unidade cross-sectional e que o termo de erro do modelo em primeiras diferenças apresenta correlação serial de primeira ordem, o GMM-Sys, criado por Blundell e Bond (1998), apresenta uma estrutura mais consistente para obter estimadores assintoticamente eficientes. Também foi utilizado o modelo dinâmico (onde a variável dependente defasada é usada como explicativa do modelo), que gera ganhos de eficiência por 
relaxar os pressupostos de homocedasticidade. Devido ao exposto, a seguinte Equação (1) é apresentada:

$$
\begin{gathered}
\text { End }_{i t}=\beta_{0}+\beta_{1} \text { End }_{i t-1}+\beta_{2} Q_{i t}+\beta_{3} \operatorname{Re}_{i t}+\beta_{4} \text { Tang }_{i t}+\beta_{5} \text { Tam }_{i t}++\beta_{6} \text { Risco }_{i t}+ \\
\beta_{7} \text { PósCrise }_{t}+\beta_{8}{\text { Var } \operatorname{Re} c_{r t}}_{\text {O }}+\sum \text { EFTemp }+\sum E \text { EFind }+\mu_{i t}
\end{gathered}
$$

Sendo, End $_{i t}$ - Endividamento; $\beta$ - Intercepto ou coeficiente angular; Alit-1 - variável dinâmica; $Q_{i t}-Q$ de Tobin; Rent $_{i t}$ - Índice de rentabilidade; Tang it $_{-}$-Tangibilidade dos ativos; Tam $_{i t}$ - Tamanho; Risco ${ }_{i t}$ - Risco do negócio; PósCrise ${ }_{t}$ - Dummy pós-crise; VarRecit - Variação da Receita; $\Sigma$ EFtemp - Efeitos fixos temporais; $\Sigma$ EFind - Efeitos fixos industriais; $\mu_{\text {it }}-$ Termo de erro; $\mathrm{i}$-Empresas; $\mathrm{t}$ - tempo.

Neste sentido, utilizou-se como variável dependente o endividamento das empresas, enquanto determinante da estrutura de capital das firmas. Com isso, utilizou-se a fórmula para calcular o endividamento proposta nos estudos de Deangelo e Roll (2015), Lang et al., (1996) e Rajan e Zingales (1995), os quais relacionam o capital de terceiros com o patrimônio líquido das empresas.

Além disso, para captar possíveis determinantes do endividamento das empresas, constituiu-se as variáveis independentes. Neste sentido, as oportunidades de crescimento foram medidas por meio do $Q$ de Tobin, que conforme estudos de Dang (2011), Lang et al., (1996) e Myers (1984) é calculado pela razão entre o valor de mercado e o total dos ativos das empresas.

Para apurar o quão rentável as empresas são, utilizou-se como métrica de rentabilidade o retorno sobre o ativo (Return on Assests - ROA). Estudos como Dang (2011), Frank e Goyal (2009) e Myers (1984) mensuraram o ROA por meio da razão do Lucro Líquido pelo ativo total das firmas. Já para apurar o nível de tangibilidade dos ativos, utilizou-se fórmula proposta por estudos com Dang (2011) e Almeida e Campello (2007), os quais dividem o valor dos ativos imobilizados pelo ativo total das empresas.

Nesta mesma linha, para apurar o tamanho das empresas foi utilizado a métrica de trabalhos como Dang (2011), Frank e Goyal (2009) e Rajan e Zingales (1996), os quais aplicam o logaritmo neperiano no valor do ativo total. Ademais, amparado em estudos como Rajan e Zingales (1996) e Toy et al., (1974) utilizou-se como medida de risco do negócio o desvio padrão da divisão do EBIT pelo ativo total das empresas.

A respeito da variabilidade dos ganhos das firmas, baseou-se em estudos como Harris e Raviv (1991) e Frank e Goyal (2009), e calculou-se a variação das receitas em relação ao ativo total das empresas. Por fim, para captar os efeitos da crise de 2008 , constituiu-se uma variável dummy, em que se atribuiu 1 (um) aos três anos seguintes a crise (2008), e 0 (zero) para os demais anos analisados, métrica utilizada em trabalhos como Anand et al., (2013) e Bem-David et al., (2012). Para melhor apresentação das variáveis, elaborou-se o quadro 1. 
Quadro 1 - variáveis utilizadas no modelo

\begin{tabular}{|c|c|c|c|c|}
\hline Variáveis & Fórmulas & Autores & Sinal & Descrição \\
\hline \multicolumn{5}{|c|}{ Dependente } \\
\hline Endividamento & $\frac{\text { Pas.Cir. + Pas.não Cir. (1) }}{\text { Patrimônio Líquido }}$ & $\begin{array}{l}\text { Deangelo e Roll } \\
\text { (2015); Lang et } \\
\text { al. (1996); Rajan } \\
\text { e Zingales } \\
\text { (1995) }\end{array}$ & & $\begin{array}{l}\text { Relação entre capital de } \\
\text { terceiros e capital próprio. }\end{array}$ \\
\hline & & Independente & & \\
\hline \multirow[t]{2}{*}{ Q de Tobin } & \multirow{2}{*}{$\frac{\text { Valor de Mercado }}{\text { Ativo Total }}$} & \multirow{2}{*}{$\begin{array}{l}\text { Dang (2011); } \\
\text { Lang et al. } \\
\text { (1996); Myers } \\
\text { (1984) }\end{array}$} & + & $\begin{array}{l}\text { Quanto maiores as } \\
\text { oportunidades de crescimento, } \\
\text { mais as empresas buscam } \\
\text { dívidas. }\end{array}$ \\
\hline & & & - & $\begin{array}{l}\text { Quanto maior as oportunidades } \\
\text { de crescimento menos as } \\
\text { empresas se endividam. }\end{array}$ \\
\hline \multirow[b]{2}{*}{$\begin{array}{l}\text { Rentabilidade: } \\
\text { - Retorno sobre } \\
\text { o ativo (ROA) }\end{array}$} & \multirow{2}{*}{$\frac{\text { Lucro Líquido }}{\text { Ativo Total }}$} & \multirow{2}{*}{$\begin{array}{l}\text { Dang (2011); } \\
\text { Frank e Goyal } \\
\text { (2009); Myers } \\
\text { (1984); }\end{array}$} & $\begin{array}{l}\text { Pecking } \\
\operatorname{order}(-)\end{array}$ & $\begin{array}{l}\text { Quanto mais lucrativas, menos } \\
\text { as empresas recorrem a dívidas. }\end{array}$ \\
\hline & & & $\begin{array}{l}\text { Trade off } \\
(+)\end{array}$ & $\begin{array}{c}\text { A empresa deve elevar seu } \\
\text { endividamento até certo ponto } \\
\text { ótimo, no qual o valor do WACC } \\
\text { é mínimo. }\end{array}$ \\
\hline Tangibilidade & $\frac{\text { Imobibiliz ado }}{\text { Ativo Total }}$ & $\begin{array}{c}\text { Dang (2011); } \\
\text { Almeida e } \\
\text { Campello (2007) }\end{array}$ & + & $\begin{array}{l}\text { Ativos que servem como } \\
\text { garantias são importantes para } \\
\text { conseguir mais financiamentos. }\end{array}$ \\
\hline $\begin{array}{l}\text { Tamanho: } \\
\text { Ativo Total }\end{array}$ & $\log$ (Ativo Total) & $\begin{array}{l}\text { Dang (2011); } \\
\text { Frank e Goyal } \\
\text { (2009); Rajan e } \\
\text { Zingales (1995). }\end{array}$ & + & $\begin{array}{c}\text { Empresas maiores geralmente } \\
\text { têm menos restrições } \\
\text { financeiras, optando por } \\
\text { umendividamento maior. }\end{array}$ \\
\hline $\begin{array}{l}\text { Risco do } \\
\text { negócio }\end{array}$ & $\sigma\left(\frac{E B I T}{\text { AtivoTotal }}\right)$ & $\begin{array}{c}\text { Rajan e Zingales } \\
\text { (1995); Toy et } \\
\text { al. (1974) }\end{array}$ & + & $\begin{array}{l}\text { O custo de falência é maior } \\
\text { para empresas com maior } \\
\text { variabilidade dos resultados. }\end{array}$ \\
\hline Pós-Crise & $\begin{array}{l}\text { Dummy: } 1 \text { - três anos } \\
\text { posteriores à crise de } \\
\text { 2008; 0 - Caso } \\
\text { Contrário. }\end{array}$ & $\begin{array}{l}\text { Anand et al. } \\
\text { (2013); Bem- } \\
\text { David et al. } \\
\text { (2012) }\end{array}$ & - & $\begin{array}{l}\text { O período pós-crise traz } \\
\text { inseguranças no mercado, } \\
\text { gerando mais cautela das } \\
\text { empresas em adquirirem } \\
\text { dívidas e dos bancos em }\end{array}$ \\
\hline $\begin{array}{l}\text { Variação da } \\
\text { receita }\end{array}$ & $\frac{\text { Receita }_{t}-\text { Receita }_{\mathrm{t}-1}}{\text { Ativo Total }}$ & $\begin{array}{l}\text { Harris e Raviv } \\
\text { (1991); Frank e } \\
\text { Goyal (2009) }\end{array}$ & + & $\begin{array}{l}\text { Quanto maior as oscilações da } \\
\text { receita da empresa, maior a } \\
\text { possibilidade de recorrer a } \\
\text { capital de terceiros. }\end{array}$ \\
\hline
\end{tabular}

Fonte: Elaborado pelos autores.

Para entender melhor a dinâmica do endividamento ao longo dos anos e entre os grupos, foi criada a figura 1 que contempla o plot do endividamento. 
Figura 1 - Box-Plot do endividamento por ano e por grupos

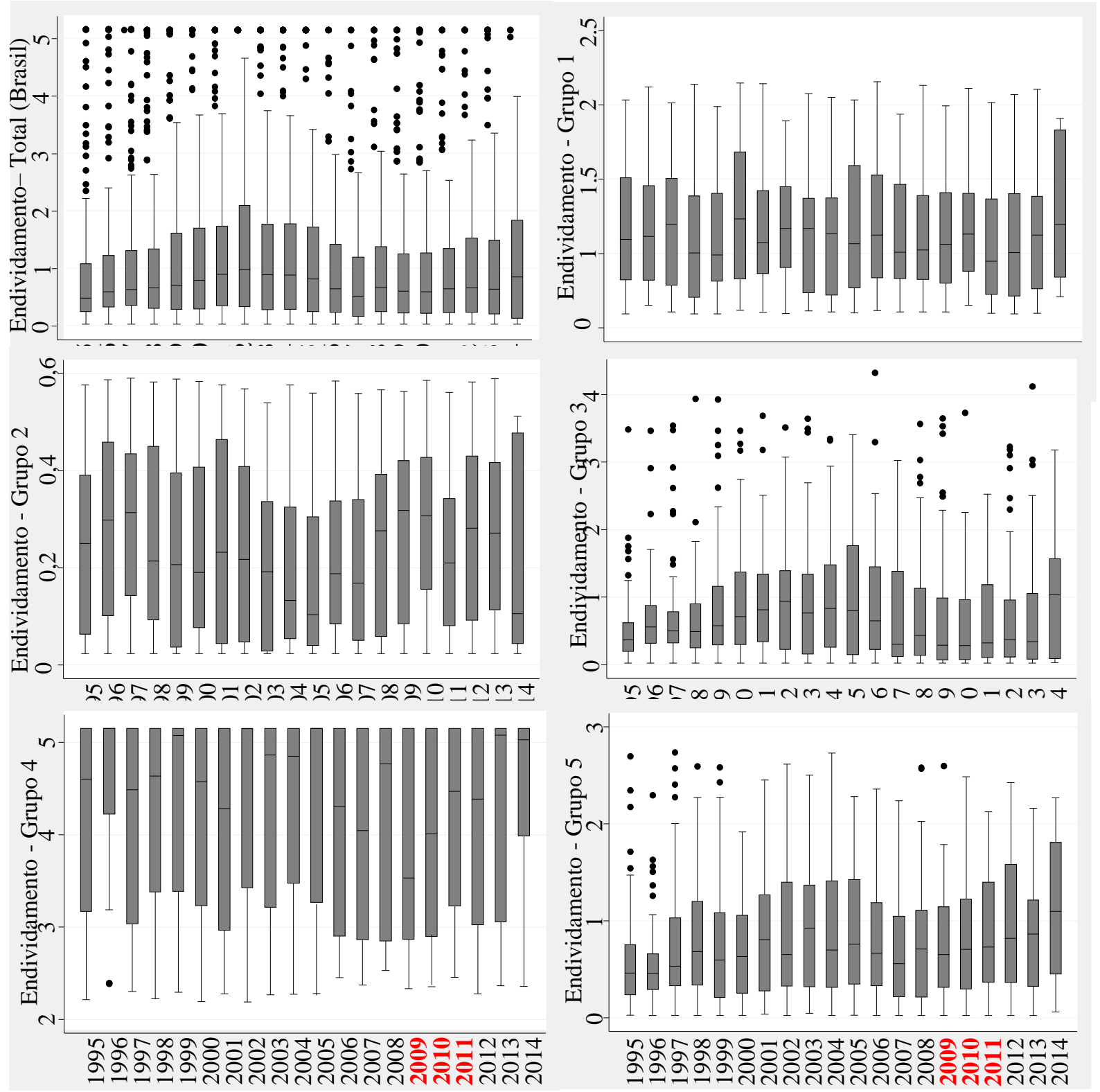

Legenda: P-valores do teste Z para a análise total: 2008(0,15); 2009(0,01***); 2010(0,01***); 2011(0,03**); 2012(0,38); 2013(0,47); 2014(0,11). *** Significativo a 1\%; ** Significativo a 5\%.

Fonte: Elaborado pelos autores.

$\mathrm{Na}$ análise com a amostra total, fica evidenciado que, nos anos que antecederam a crise de 2008 , houve um significativo aumento no endividamento, situação que se inverteu no período posterior a esse marco onde, nos três anos subsequentes, as empresas diminuíram significativamente o seu endividamento (comprovado através do teste $Z$ de diferença entre médias apresentado na legenda da Figura 1), retomando o financiamento de recursos externos a partir de 2012. Esse padrão é encontrado em praticamente todas as análises, com exceção dos grupos 2 e 4, que apresentaram, respectivamente, o menor e maior endividamento, com diferença estatisticamente significativa, como pode ser observado na Tabela 1. Esse resultado ocorre, provavelmente, devido a maior cautela das empresas em se 
endividarem em momentos de crise, também devido ao fato de os bancos ficarem mais rigorosos nos empréstimos bancários, como evidenciado por Schularick e Taylor (2012).

Além disso, para a estatística descritiva, foi criada a Tabela 1, contendo os dados gerais antes e após a crise e os dados divididos por grupos.

Tabela 1 - Estatística Descritiva

\begin{tabular}{|c|c|c|c|c|c|c|c|}
\hline & Endividamento & Q Tobin & ROA & Tangibilidade & Ativo Total' & Risco & Var. da Receita' \\
\hline \multicolumn{8}{|c|}{ Amostra total (Brasil) } \\
\hline Média & 1,14 & 1,38 & 0,04 & 0,06 & 17,95 & 0,07 & 0,15 \\
\hline Mediana & 0,66 & 0,98 & 0,04 & 0,01 & 6,64 & 0,05 & 0,04 \\
\hline Variância & 1,75 & 1,41 & 0,01 & 0,01 & $194.532,00$ & 0,00 & $7.323,79$ \\
\hline Des.Pad. & 1,32 & 1,19 & 0,09 & 0,07 & 27,07 & 0,06 & 5,24 \\
\hline \multicolumn{8}{|c|}{ Amostra total antes da crise } \\
\hline Média & 1,19 & 1,17 & 0,04 & 0,06 & 17,23 & 0,07 & 0,26 \\
\hline Mediana & 0,68 & 0,77 & 0,04 & 0,03 & 6,15 & 0,05 & 0,04 \\
\hline Variância & 1,88 & 1,24 & 0,01 & 0,01 & $186.615,00$ & 0,00 & $4.689,54$ \\
\hline Des.Pad. & 1,37 & 1,12 & 0,09 & 0,07 & 26,54 & 0,06 & 4,22 \\
\hline$p$-valor & 0,27 & $0,01 * * *$ & 0,48 & 0,48 & $0,00 * * *$ & 0,45 & $0,00 * * *$ \\
\hline \multicolumn{8}{|c|}{ Amostra total pós-crise } \\
\hline Média & 1,04 & 1,79 & 0,05 & 0,05 & 19,26 & 0,07 & $-0,08$ \\
\hline Mediana & 0,64 & 1,45 & 0,05 & 0,00 & 7,95 & 0,05 & 0,00 \\
\hline Variância & 1,46 & 1,47 & 0,01 & 0,00 & $208.858,00$ & 0,00 & $11.666,57$ \\
\hline Des.Pad. & 1,21 & 1,21 & 0,09 & 0,07 & 28,05 & 0,06 & 6,64 \\
\hline$p$-valor & $0,10^{*}$ & $0,00 * * *$ & 0,46 & 0,46 & $0,00 * * *$ & 0,50 & $0,00 * * *$ \\
\hline \multicolumn{8}{|c|}{ Grupo 1} \\
\hline Média & 1,14 & 1,55 & 0,04 & 0,08 & 22,73 & 0,05 & 0,15 \\
\hline Mediana & 1,07 & 1,20 & 0,04 & 0,05 & 8,93 & 0,04 & 0,08 \\
\hline Variância & 0,17 & 1,45 & 0,01 & 0,01 & $255.606,00$ & 0,00 & $2.250,88$ \\
\hline Des.Pad. & 0,41 & 1,21 & 0,07 & 0,07 & 31,03 & 0,05 & 2,90 \\
\hline$p$-valor & 0,47 & $0,03 * *$ & 0,49 & 0,41 & $0,00 * * *$ & 0.44 & $0,00 * * *$ \\
\hline \multicolumn{8}{|c|}{ Grupo 2} \\
\hline Média & 0,25 & 1,46 & 0,07 & 0,03 & 14,18 & 0,08 & 0,15 \\
\hline Mediana & 0,23 & 1,05 & 0,07 & 0,00 & 5,62 & 0,06 & 0,04 \\
\hline Variância & 0,03 & 1,46 & 0,01 & 0,00 & $131.196,00$ & 0,00 & $1.519,42$ \\
\hline Des.Pad. & 0,18 & 1,21 & 0,09 & 0,05 & 22,24 & 0,06 & 2,38 \\
\hline$p$-valor & $0,00 * * *$ & 0,18 & 0,38 & 0,38 & $0,00 * * *$ & 0.46 & $0,00 * * *$ \\
\hline \multicolumn{8}{|c|}{ Grupo 3} \\
\hline Média & 0,78 & 1,30 & 0,04 & 0,04 & 22,73 & 0,07 & 0,26 \\
\hline Mediana & 0,51 & 0,95 & 0,05 & 0,00 & 9,88 & 0,05 & 0,04 \\
\hline Variância & 0,64 & 1,18 & 0,01 & 0,00 & $246.181,00$ & 0,00 & $20.012,89$ \\
\hline Des.Pad. & 0,80 & 1,09 & 0,09 & 0,07 & 30,46 & 0,06 & 8,67 \\
\hline$p$-valor & $0,00 * * *$ & 0,18 & 0,48 & 0,44 & $0,00 * * *$ & 0,50 & $0,00 * * *$ \\
\hline \multicolumn{8}{|c|}{ Grupo 4} \\
\hline Média & 4,19 & 1,62 & $-0,03$ & 0,07 & 15,53 & 0,09 & $-0,04$ \\
\hline Mediana & 4,69 & 1,09 & $-0,01$ & 0,06 & 4,37 & 0,06 & 0,00 \\
\hline Variância & 1,10 & 2,02 & 0,01 & 0,01 & $172.289,00$ & 0,00 & $3.053,25$ \\
\hline Des.Pad. & 1,05 & 1,42 & 0,08 & 0,07 & 25,49 & 0,07 & 3,39 \\
\hline$p$-valor & $0,00 * * *$ & $0,00 * * *$ & 0,21 & 0,43 & $0,00 * * *$ & 0,42 & $0,00 * * *$ \\
\hline \multicolumn{8}{|c|}{ Grupo 5} \\
\hline Média & 0,80 & 1,16 & 0,05 & 0,07 & 12,44 & 0,06 & 0,04 \\
\hline Mediana & 0,65 & 0,80 & 0,05 & 0,06 & 4,22 & 0,04 & 0,00 \\
\hline Variância & 0,40 & 1,17 & 0,01 & 0,01 & $122.902,00$ & 0,00 & 2400,96 \\
\hline Des.Pad. & 0,63 & 1,08 & 0,08 & 0,08 & 21,53 & 0,06 & 3,02 \\
\hline$p$-valor & $0,00 * * *$ & $0,00 * * *$ & 0,46 & 0,42 & $0,00 * * *$ & 0,47 & $0,00 * * *$ \\
\hline
\end{tabular}

Legenda: ${ }^{* *}$ - Sig. 1\% (0,01); ${ }^{* *}$ - Sig. 5\% (0,05); * - Sig. 10\% (0,1). ${ }^{1}$ Em milhões.

Fonte: Elaborado pelos autores. 
Conforme a Tabela 1, algumas variáveis apresentaram disparidades muito grandes entre a média e a mediana, com variâncias e desvios-padrão elevados, as quais foi aplicada a winsorização a $1 \%$. Também foi aplicado o teste $Z$ para comparação de médias, a fim de verificar se existe diferença significativa dos grupos com relação à amostra total. Além disso, a tabela 2 apresenta os resultados do teste (Z) para verificar a diferença das médias entre os grupos.

Tabela 2 - Teste $Z$ - diferença de médias entre os grupos

\begin{tabular}{|c|c|c|c|c|c|c|c|}
\hline & Endividamento & Q Tobin & ROA & Tangibilidade & Ativo Total & Risco & Var. da Receita \\
\hline \multicolumn{8}{|c|}{ Grupos 1 e 2} \\
\hline Teste $z$ & $-18,48$ & $-1,69$ & 0,64 & $-0,97$ & $-4,70$ & 0,46 & $-1,10$ \\
\hline $\mathrm{p}$-Valor & $0,00 * * *$ & $0,04 * *$ & 0,26 & 0,16 & $0,00 * * *$ & 0,32 & $0,00 * * *$ \\
\hline \multicolumn{8}{|c|}{ Grupos 1 e 3} \\
\hline Teste $z$ & $-8,15$ & $-5,47$ & 0,17 & $-0,72$ & $-92,83$ & 0,28 & 525,62 \\
\hline p-Valor & $0,00 * * *$ & $0,00 * * *$ & 0,43 & 0,23 & $0,00 * * *$ & 0,38 & $0,00 * * *$ \\
\hline \multicolumn{8}{|c|}{ Grupos 1 e 4} \\
\hline Teste $z$ & 54,42 & 1,30 & $-1,19$ & $-0,05$ & $-3,40$ & 0,54 & $-7,70$ \\
\hline p-Valor & $0,00 * * *$ & $0,09 * * *$ & 0,11 & 0,47 & $0,00 * * *$ & 0,29 & $0,00 * * *$ \\
\hline \multicolumn{8}{|c|}{ Grupos 1 e 5} \\
\hline Teste $z$ & $-7,24$ & $-8,19$ & 0,24 & $-0,02$ & $-5,70$ & 0,12 & $-5,60$ \\
\hline p-Valor & $0,00 * * *$ & $0,00 * * *$ & 0,40 & 0,49 & $0,00 * * *$ & 0,45 & $0,00 * * *$ \\
\hline \multicolumn{8}{|c|}{ Grupos 2 e 3} \\
\hline Teste $z$ & 12,41 & $-3,78$ & $-0,54$ & 0,34 & 5,30 & $-0,22$ & 658,87 \\
\hline p-Valor & $0,00 * * *$ & $0,00 * * *$ & 0,29 & 0,36 & $0,00 * * *$ & 0,41 & $0,00 * * *$ \\
\hline \multicolumn{8}{|c|}{ Grupos 2 e 4} \\
\hline Teste $z$ & 72,34 & 2,85 & $-1,79$ & 0,81 & 6,60 & 0,14 & $-6,80$ \\
\hline p-Valor & $0,00 * * *$ & $0,00 * * *$ & $0,03 * *$ & 0,20 & $0,00 * * *$ & 0,44 & $0,00 * * *$ \\
\hline \multicolumn{8}{|c|}{ Grupos 2 e 5} \\
\hline Teste $z$ & 12,09 & $-6,69$ & $-0,42$ & 1,01 & $-1,00$ & $-0,36$ & $-4,40$ \\
\hline p-Valor & $0,00 * * *$ & $0,00 * * *$ & 0,33 & 0,15 & $0,00 * * *$ & 0,35 & $0,00 * * *$ \\
\hline \multicolumn{8}{|c|}{ Grupos 3 e 4} \\
\hline Teste $z$ & 66,70 & 6,21 & $-1,45$ & 0,57 & $-3,70$ & 0,34 & $-1,30$ \\
\hline p-Valor & $0,00 * * *$ & $0,00 * * *$ & $0,07 *$ & 0,28 & $0,00 * * *$ & 0,36 & $0,00 * * *$ \\
\hline \multicolumn{8}{|c|}{ Grupos 3 e 5} \\
\hline Teste $z$ & 0,50 & $-3,46$ & 0,09 & 0,75 & $-6,50$ & $-0,16$ & $-1,20$ \\
\hline p-Valor & 0,30 & $0,00 * * *$ & 0,46 & 0,22 & $0,00 * * *$ & 0,41 & $0,00 * * *$ \\
\hline \multicolumn{8}{|c|}{ Grupos 4 e 5} \\
\hline Teste $z$ & $-63,29$ & $-8,62$ & 1,46 & 0,03 & $-1,50$ & $-0,46$ & 330,40 \\
\hline p-Valor & $0,00 * * *$ & $0,00 * * *$ & $0,07 *$ & 0,48 & $0,00 * * *$ & 0,32 & $0,00 * * *$ \\
\hline
\end{tabular}

Legenda: *** - Sig. 1\% (0,01); ** - Sig. 5\% (0,05); * - Sig. 10\% (0,1.

Fonte: Elaborado pelos autores.

Analisando os dados totais, percebe-se que, em termos de endividamento, o capital de terceiros, em média, é $14 \%$ maior que o capital próprio, ou seja, para cada $\mathrm{R} \$ 1,00$ de capital próprio, a empresa se endivida em $\mathrm{R} \$ 1,14$. Tratando-se do $Q$ de Tobin, o valor de mercado supera, em média, $38 \%$ o valor patrimonial. Em relação ao retorno sobre o ativo (ROA), em média, o lucro representa $4 \%$ do ativo total. Os ativos imobilizados representam em torno de $6 \%$ do ativo total das empresas. Já o risco de não obter o retorno desejado dos ativos atingiu, em média, 7\%. O ativo total das empresas gira em torno de $\mathrm{R} \$ 17,95$ milhões, já a variação da receita de um ano para outro atinge, em média $\mathrm{R} \$ 150$ mil. Considerando o período antes e após a crise, percebe-se que o endividamento diminuiu, significativamente de acordo com teste de hipótese, sendo que a média desta variável é significativamente diferente da média geral no pós-crise. Também, nesse período, é notado um aumento significativo do $Q$ de Tobin e do ativo total e uma diminuição da variação da receita. 
Comparando os grupos com a amostra completa, percebe-se que o grupo 4 é o que mais apresenta discrepâncias. Nesse grupo, o endividamento é quase quatro vezes maior que na amostra total, o valor de mercado supera em $62 \%$ o valor patrimonial das empresas e a variação da receita é a menor entre os grupos, sendo que todas as médias são significativamente diferentes a $1 \%$. Esse grupo também apresenta o menor retorno do ativo e o maior risco, mas essas médias não são estatisticamente significativas. 0 grupo dois também se destaca, mas no sentido oposto, pois apresentou o menor endividamento, chegando à quarta parte da média geral, significativa a 1\%. Esse grupo também apresenta o maior retorno do ativo e a menor tangibilidade, apesar de não serem significativas. Esse resultado está em compasso com a teoria de pecking order de Myers (1984), o qual afirma que as empresas mais rentáveis buscam menos capital de terceiros. Outro motivo para o baixo endividamento é o fato de possuírem menos ativos para oferecerem em garantia (Almeida \& Campello, 2007).

Outros grupos também merecem destaque. O grupo 1 apresenta, juntamente com o grupo 3, o maior ativo total, com $\mathrm{R} \$ 22,73$ milhões, significativamente diferentes da média geral a $1 \%$. O grupo 1 também apresenta a maior tangibilidade e o menor risco, mas essas variáveis não são significativas. O grupo 3 apresenta maior variação da receita, com R\$ 26 mil. Por fim, o grupo 5 apresenta o menor $Q$ de Tobin, indicando que o valor de mercado supera em $16 \%$ o valor patrimonial, e o menor ativo total, em torno de $\mathrm{R} \$ 12,44$ milhões, ambas significativas a $1 \%$. As variáveis que apresentaram alta correção não foram usadas na mesma análise.

Quanto a diferença de médias entre os grupos, nas variáveis $Q$ de Tobin, ativo total e variação de receita os testes apontam que há diferença das médias em todas as análises entre grupos. Por outro lado, quanto testadas as variáveis tangibilidade e risco do negócio, o teste (Z) indica que não existe diferença entre as médias para todas as análises entre grupos. Já no caso da variável de endividamento, há diferença entre as médias em todas as análises, exceto quando testado as médias entre os grupos 3 e 5 . Com relação a variável retorno dos ativos (ROA) existe diferença entre as médias nas análises entre os grupos 2 e 4; 3 e 4; e 4 e 5, nos demais não há diferenças entre as médias. Ademais, para realizar a análise, foram aplicados os seguintes testes: (i) correlação; (ii) Arellano e Bond (1991): verifica a existência de correlação serial; (iii) sobreidentificação de Hansen (1982); e, (iv) qui-quadrado ( $\chi^{2}$ ). As variáveis foram winsorizadas a $1 \%$ (foram eliminados os dados extremos) e corrigidas pelo IGP-DI.

\section{ANÁLISE DOS RESULTADOS}

Para verificar a influência dos determinantes financeiros no endividamento, é elaborada a Tabela 3, que apresenta os resultados de diversos testes. Neles é evidenciado que o método GMM-Sys é o mais ajustado para o estudo. As regressões são divididas em três análises. Na primeira, é considerada a amostra total, que é dividida em duas partes (antes e depois da crise de 2008) para compor a segunda análise. Por fim, essa amostra é dividida em 5 grupos de acordo com a classificação feita pela análise de cluster. Em geral o endividamento é influenciado positivamente pelo $Q$ de Tobin em praticamente todas as análises (exceto a do grupo 2), ou seja, quanto maior o valor de mercado com relação ao valor patrimonial, mais a empresas se endividam. Esse resultado corrobora com Lang et al. (1996), os quais afirmaram que, quanto mais oportunidades de crescimento, mais as empresas buscam dívidas. Essa influência positiva e significativa tem mais relação com o período pós-crise, pois a referida 
variável não foi significativa no período anterior a esse marco, como pode ser verificado nas duas últimas regressões.

Em se tratando da rentabilidade, mesmo que com uma baixa significância, essa variável influencia negativamente o endividamento em todas as análises, corroborando com os conceitos de pecking order de Myers (1984), os quais afirmaram que, quanto mais lucrativas as empresas são, menos precisam recorrer a dívidas. Essa relação também ocorre devido ao período pós-crise, já que a rentabilidade não foi significativa na regressão referente ao período anterior à crise de 2008. Com relação à tangibilidade dos ativos, essa variável é positiva e significativa somente nos grupos 2 e 3, evidenciando que, neles, quanto mais imobilizados as empresas possuem, mais recorrem à capitais de terceiros. Esse resultado também foi encontrado por Almeida e Campello (2007), os quais indicaram que, quanto mais ativos as empresas têm, mais garantias possuem para obter financiamentos.

Tabela 3 - Análises setoriais do endividamento das empresas

\begin{tabular}{|c|c|c|c|c|c|c|c|c|}
\hline Variável & Total & Grupo 1 & Grupo 2 & Grupo 3 & Grupo 4 & Grupo 5 & Pré-crise & Pós-Crise \\
\hline Endividamentot-1 & $0,40 * * *$ & $0,23 * * *$ & $0,13^{*}$ & $0,53 * * *$ & $0,68 * * *$ & $0,51 * * *$ & $0,57 * * *$ & $0,50 * * *$ \\
\hline Q de Tobin & $0,27 * * *$ & $0,20 * * *$ & 0,04 & $0,12 * *$ & $0,21 * * *$ & $0,10 * *$ & 0,08 & $0,39 * * *$ \\
\hline Rentabilidade & $-0,04 * * *$ & $-0,03 * * *$ & $-0,01 * *$ & $-0,03 * * *$ & $-0,05 * * *$ & $-0,02 * * *$ & $-0,01$ & $-0,04 * * *$ \\
\hline Tangibilidade & 0,01 & 0,00 & $0,03 * * *$ & $0,04 * * *$ & $-0,02$ & 0,01 & $-0,05$ & 0,07 \\
\hline Tamanho & $0,64 *$ & $0,19 * * *$ & 0,06 & $0,14 * *$ & 0,03 & 0,01 & $0,98 *$ & $0,45^{* *}$ \\
\hline Risco & 0,01 & 0,00 & 0,00 & 0,00 & $0,03^{*}$ & 0,00 & 0,01 & $0,02 *$ \\
\hline Pós-Crise & $-0,32 * *$ & $-0,02$ & $-0,23$ & $-0,27^{*}$ & $-1,08 * * *$ & $-0,23$ & $\begin{array}{l}- \\
-\end{array}$ & - \\
\hline Var. Receita & $1,37^{* *}$ & 0,30 & $0,24 * *$ & $0,69 *$ & $-0,04$ & $-0,05$ & 1,83 & 0,15 \\
\hline Constante & $-57,40$ & 8,87 & 1,26 & 0,15 & 1,45 & 0,16 & $-16,60$ & $-5,60 *$ \\
\hline EF Temp & Sim & Sim & Sim & Sim & Sim & Sim & Sim & Sim \\
\hline EF Ind & Sim & Sim & Sim & Sim & Sim & Sim & Sim & Sim \\
\hline Número de Obs & 4.585 & 793 & 909 & 1.347 & 533 & 1.003 & 2.857 & 1.728 \\
\hline$\chi^{2}$ & 474,92 & 364,83 & 129,85 & $1.135,41$ & $2.415,61$ & 1083,52 & 277,73 & 313,94 \\
\hline$\chi^{2} p$ & 0,00 & 0,00 & 0,00 & 0,00 & 0,00 & 0,00 & 0,00 & 0,00 \\
\hline Hansen & 159,65 & 95,77 & 77,83 & 532,00 & 168,00 & 50,68 & 50,17 & 90,20 \\
\hline Hansen $p$ & 0,21 & 1,00 & 1,00 & 1,00 & 1,00 & 1,00 & 0,15 & 0,20 \\
\hline Ar1 & $-5,11$ & $-2,97$ & $-2,16$ & $-3,31$ & $-4,13$ & $-3,97$ & $-2,98$ & $-3,27$ \\
\hline $\operatorname{Ar1} p$ & 0,00 & 0,00 & 0,03 & 0,00 & 0,00 & 0,00 & 0,00 & 0,00 \\
\hline Ar2 & 0,33 & 0,06 & $-1,18$ & $-0,68$ & 0,53 & $-0,32$ & 0,85 & $-0,02$ \\
\hline$A r 2 p$ & 0,74 & 0,96 & 0,24 & 0,50 & 0,59 & 0,75 & 0,40 & 0,99 \\
\hline
\end{tabular}

Legenda: *** - Sig. 1\% (0,01); ** - Sig. 5\% (0,05); * Sig. 10\% $(0,1)$.

Fonte: Elaborado pelos autores. 
O tamanho das empresas somente é significativo na amostra total e nos grupos 1 e 3 , evidenciando para estes que, quanto maior a empresa, mais recorre a dívidas, corroborando com Frank e Goyal (2009), os quais indicaram que empresas maiores, geralmente têm menos restrições financeiras, optando por um endividamento maior. Tanto antes quanto depois da crise essa variável se mostra positiva e significativa, ou seja, as maiores empresas continuaram se endividando mais, mesmo após a crise. Quanto maior o risco do negócio, mais as empresas pertencentes ao grupo 4 recorrem ao endividamento, sendo que esse resultado foi significativo no pós-crise, evidenciando que, após esse período, o custo de falência ficou maior para empresas mais arriscadas, corroborando com Rajan e Zingales (1995).

Ao avaliar o período pós-crise nas regressões, é evidenciado que este influenciou negativamente o endividamento para a amostra total e para os grupos 3 e 4 . O referido resultado está em compasso com Anand et al. (2013), os quais afirmaram que o período póscrise trouxe inseguranças ao mercado, gerando mais cautela das empresas em adquirirem dívidas e dos bancos em liberarem empréstimos.

Por fim, a variação da receita afeta positivamente o endividamento, ou seja, um aumento na receita da empresa com relação ao período anterior, gera um maior endividamento para a amostra total e para os grupos 2 e 3, comprovando os achados de Frank e Goyal (2009), os quais evidenciaram que, quanto maior as oscilações da receita da empresa, maior a possibilidade de recorrer à capital de terceiros. Essa variável passa a não ser significativa quando a amostra é dividida nos períodos pré e pós-crise. $O$ endividamento em um período anterior afeta significativamente o mesmo em um período subsequente em todas as análises, indicando assim que o vetor autoregressivo é significativo. Esse resultado corrobora com a estabilidade da estrutura de capital ao longo do tempo, prevista por Lemmon et al. (2008), os quais indicam que o endividamento de um período anterior influencia em períodos futuros.

Na parte inferior da Tabela 2 são apresentados os testes de validação do modelo proposto. Neste sentido, ao verificar a sobreidentificação de Hansen (1982) evidencia-se que, em todas as análises, não é rejeitada a hipótese nula, indicando que os instrumentos não são relacionados com o erro. No teste Qui-quadrado $\left(\chi^{2}\right)$, é rejeitada a hipótese nula, indicando que existe associação entre as variáveis do modelo. Por fim, no teste de Arellano e Bond (1991), em todas as análises é rejeitada a hipótese de ausência de correlação serial nos resíduos de primeira ordem e não é rejeitada para os de segunda ordem. Portanto, o modelo tem correlação serial de ordem 1, justificando o uso do GMM-Sys e do modelo dinâmico.

\section{CONSIDERAÇÕES FINAIS}

O presente trabalho buscou analisar os determinantes das oscilações no endividamento das empresas brasileiras de capital aberto após a crise de 2008, identificando se os efeitos dessa crise foram sentidos de forma diferenciada para grupos classificados de acordo com o nível de endividamento. Neste sentido, os resultados do modelo indicam a não rejeitação da hipótese $\mathrm{HO}$, ou seja, os determinantes financeiros afetam de forma significativa as empresas. Esses achados corroboram com Anand et al. (2013), Acharya e Mora (2015), Bliss et al. (2015) e Beber e Pagano (2013). Além disso, ao analisar os determinantes do endividamento por meio de cruster, os resultados do presente estudo permitem uma análise mais detalhada, levando em conta peculiaridades e diferenças das empresas brasileiras, quanto aos seus financiamentos externos. 
No geral, as empresas que possuem maior valor de mercado com relação ao valor patrimonial apresentam maior endividamento, sendo que esse resultado é mais representativo no período posterior à crise. Trabalhos, como o de Lang et al. (1996), relataram esse fato, identificando que empresas que possuem maiores oportunidades de crescimento se endividam mais. Já as empresas mais rentáveis acabam investindo mais capital próprio, apresentando, por consequência, menores níveis de endividamento, principalmente após a crise, corroborando com a teoria de pecking order de Myers (1984) e com Acharya e Mora (2015), os quais afirmaram que, após a crise, os bancos limitaram o crédito.

A tangibilidade dos ativos somente foi significativa nos grupos menos endividados $(2 \mathrm{e}$ 3), mostrando que para esses, quanto mais ativos imobilizados as empresas têm, mais garantias possuem para obter capitais de terceiros, corroborando com Almeida e Campello (2007). Quanto maior o tamanho da empresa, medido pelos ativos totais, mais as empresas se endividam, sendo que esse resultado foi observado tanto antes quanto após a crise de 2008, evidenciando que as maiores empresas continuaram se endividando mesmo no póscrise. Esse resultado está em compasso com Frank e Goyal (2009). Também ficou evidenciado que o custo de falência ficou maior para empresas mais arriscadas no pós-crise, corroborando com Rajan e Zingales (1995). Quanto maior as oscilações da receita das empresas dos grupos 2 e 3 e da análise com a amostra total, maior a possibilidade destas recorrerem a capital de terceiros, em compasso com os achados de Frank e Goyal (2009).

Conforme evidenciado na análise gráfica, a crise somente afetou de uma forma significativa o endividamento nos três períodos posteriores à crise. Esse resultado também foi encontrado nas regressões, onde esse período influenciou negativamente o endividamento para a amostra geral e para os grupos 3 e 4, corroborando com Anand et al. (2013). Essas inferências levam a crer que, depois da crise, as empresas ficaram mais receosas em buscar dívidas, também, os bancos começaram a ser mais rigorosos na concessão de crédito, sendo que as empresas maiores e mais arriscadas, com mais oportunidades de crescimento e menor rentabilidade, foram as mais suscetíveis a se endividarem no período pós-crise. Acredita-se que uma análise mais acurada quanto a estrutura de capital e o impacto do vetor autoregressivo no endividamento das firmas seriam bons caminhos para novas pesquisas.

\section{REFERÊNCIAS}

ACHARYA, V. V.; MORA, N. A crisis of banks as liquidity providers. The Journal of Finance, v. 70, n. 1, 2015. DOI: https://doi.org/10.1111/jofi.12182.

ALMEIDA, H.; CAMPELLO, M. Financing constraints, asset tangibility, and corporate investment. Review of Financial Studies, v. 20, p. 1429-1460, set. 2007. DOI: https://doi.org/10.1093/rfs/hhm019.

ALMEIDA, H., CAMPELLO, M.; GALVÃO, A. F. Measurement errors in investment equations. Review of Financial Studies, v. 23, n.9, p. 3279-3328, abril 2010. DOI: 10.3386/w15951.

ANAND, A., IRVINE, P., PUCKETT, A.; VENKATARAMAN, K. Institutional trading and stock resiliency: Evidence from the 2007-2009 financial crisis. Journal of Financial Economics, $v$. 108, n. 3, p. 773-797, jun. 2013. DOI: https://doi.org/10.1016/j.jfineco.2013.01.007. 
ANDRADE, G.; KAPLAN, S. How costly is financial (not economic) distress? evidence from highly leveraged transactions that become distressed. The Journal of Finance, v. 53, n. 5, p. 1443-1493, out 1998. DOI: https://doi.org/10.1111/0022-1082.00062.

ARELLANO, M.; BOND, S. Some tests of specification for panel data: Monte Carlo evidence and an application to employment equations. Review of Economic Studies, v. 58, n. 2, p. 277-297, abril 1991. DOI: https://doi.org/10.2307/2297968.

BEBER, A.; PAGANO, M. Short-selling bans around the world: evidence from the 2007-09 crisis. The Journal of Finance, v. 68, n. 1, fev. 2013. DOI: https://doi.org/10.1111/j.15406261.2012.01802.x.

BEN-DAVID, I., FRANZONI, F.; MOUSSAWI, R. Hedge fund stock trading in the financial crisis of 2007-2009. The Review of Financial Studies, v. 25, n. 1, p. 1-54, jan. 2012. DOI: https://doi.org/10.1093/rfs/hhr114.

BLISS, A. B., CHENG, Y.; DENIS, J. D. Corporate payout, cash retention, and the supply of credit: Evidence from the 2008-2009 credit crisis. Journal of Financial Economics, v. 115, n. 3, p. 521-540, mar 2015. DOI: https://doi.org/10.1016/j.jfineco.2014.10.013.

BLUNDELL, R.; BOND, S. Initial conditions and moment restrictions in dynamic panel data models. Journal of Econometrics, v. 87, n. 1, p. 115-143, nov. 1998. DOI:

https://doi.org/10.1016/S0304-4076(98)00009-8.

COOKE, T.E. Disclosure in the Corporate Annual Reports of Swedish Companies. Accounting and Business Research, v. 19, n. 74, p. 113-124.

COSTA, C. S. (2015) Origens da crise e perspectivas futuras. Disponível em: $<w w w . v a l o r . c o m . b r>$. Acesso em: 15 nov. 2015.

DANG, A. V. Leverage, debt maturity and firm investment: an empirical analysis. Journal of Business Finance \& Accounting, v. 38, n. 1-2, p. 225-258, jan/mar 2011. DOI: https://doi.org/10.1111/j.1468-5957.2010.02215.x.

DEANGELO, H.; ROLL, R. How stable are corporate capital structures? The Journal of Finance, v. 70, n. 1, p. 373-418, fev. 2015. DOI: https://doi.org/10.1111/jofi.12163.

DUTRA, V. R.; SONZA, I. B.; CERETTA, P. S.; GALLI, O. C. Determinants of clash retention in Brazilian companies: An analysis after the 2008 crisis. Journal of Education and Research in Accounting, v. 12, n. 3, p. 349-363, jul-set, 2018. DOI:

http://dx.doi.org/10.17524/repec.v12i3.1808

FRANK, M. Z.; GOYAL, V. K. Capital structure decisions: which factors are reliably important? Financial management, v. 38, n. 1, p. 1-37, abr. 2009. DOI: https://doi.org/10.1111/j.1755-053X.2009.01026.x. 
GEORGE, J. T.; HWANG, Y. C. A resolution of the distress risk and leverage puzzles in the cross section of stock returns. Journal of Financial Economics, v. 96, n. 1, p. 56-79, abr. 2010. DOI: https://doi.org/10.1016/j.jfineco.2009.11.003.

GILSON, C. S. Transactions costs and capital structure choice: evidence from Financially Distressed Firms. The Journal of Finance, v. 52, n. 1, p. 161-196, mar. 1997. DOI: http://www.jstor.org/stable/2329560.

HANSEN, L. P. Large sample properties of generalized method of moments estimators. Econometrica, v. 50, n. 4, p. 1029-1054, jul. 1982. DOI: http://www.jstor.org/stable/1912775.

HARRIS, M.; RAVIV, A. The theory of capital structure. The Journal of finance, v. 46, n. 1, p. 297-355, mar. 1991. DOI: https://doi.org/10.1111/j.1540-6261.1991.tb03753.x.

HERTZBERG, A., LIBERTI, M. J.; PARAVISINI, D. Public information and coordination: evidence from a credit registry expansion. The Journal of Finance, v. 66, n. 2, p. 379-412, abr. 2011. DOI: https://doi.org/10.1111/j.1540-6261.2010.01637.x.

KAHLE, K. M.; STULZ, R. M. Access to capital, investment, and the financial crisis. Journal of Financial Economics, v. 110, n. 2, p. 280-299, nov. 2013. DOI:

https://doi.org/10.1016/j.jfineco.2013.02.014.

LANG, L., OFEK, E.; STULZ, R. Leverage, Investment and Firm Growth. Journal of Financial Economics, v. 40, n. 1, p. 3-29, jan. 1996. DOI: https://doi.org/10.1016/0304-405X(95)008423.

LEMMON, M., ROBERTS, M.; ZENDER, J. F. Back to the beginning: persistence and the crosssection of corporate capital structure. The Journal of Finance, v. 63, n. 4, p. 1-37, ago. 2008. DOI: https://doi.org/10.1111/j.1540-6261.2008.01369.x.

MITCHELL, M.; PULVINO, T. Arbitrage crashes and the speed of capital. Journal of Financial Economics, v. 104, n. 3, p. 469-490, jun. 2012. DOI: https://doi.org/10.1016/j.jfineco.2011.09.002.

MODIGLIANI, F.; MILLER, M. H. The cost of capital, corporation finance, and Theory of Investment. American Economic Review, v. 48, n. 3, p. 261-297, jun. 1958.

MURATORI, U. Contagion in the Euro Area Sovereign Bond Market. Social Sciences, v. 4, n.1, p. 66-82, dez. 2015. DOI: 10.3390/socsci4010066.

MYERS, S. C. The capital structure puzzle. The Journal of Finance, v. 39, n. 3, p. 575-592, jun. 1984. DOI: https://doi.org/10.1111/j.1540-6261.1984.tb03646.x. 
RAJAN, R.; ZINGALES, L. What do we know about capital structure? Some evidence from international data. The Journal of Finance, v. 50, n. 5, p. 1421-1460, dez. 1995. DOI: https://doi.org/10.1111/j.1540-6261.1995.tb05184.x.

SCHULARICK, M.; TAYLOR, A. M. Credit booms gone bust: monetary policy, leverage cycles, and financial crises, 1870-2008. The American Economic Review, v. 102, n. 2, p. 1029-1061, abr. 2012. DOI: 10.1257/aer.102.2.1029.

SOKOL, M. Financialisation, financial chains and uneven geographical development: Towards a research agenda. Research in International Business and Finance, v. 39, (parte B), p. 678685, 2017. DOI: https://doi.org/10.1016/j.ribaf.2015.11.007.

TIROLE, J. The Theory of Corporate Finance. Princeton: Princeton University Press, 2006.

TOY, N., STONEHILL, A., REMMERS, L., WRIGHT, R.; BEEKHUISEN, T. A comparative international study of growth, profitability and risk as determinants of corporate debt ratios in the manufacturing sector. Journal of Finance and Quantitative Analysis, v. 9, n. 5, p. 875886, nov. 1974. DOI: https://doi.org/10.2307/2329684. 